\title{
ELECTROCHEMICAL BEHAVIOUR OF COPPER IN POTASSIUM THIOCYANATE-I. DISSOLUTION, PASSIVATION AND PITTING PROCESSES
}

\author{
M. G. Figueroa,* R. C. Salvarezza and A. J. Arvia
}

Instituto de Investigaciones Fisicoquímicas Teóricas y Aplicadas (INIFTA), Casilla de Correo 16, Sucursal 4, (1900) La Plata, Argentina

(Received 20 August 1985)

\begin{abstract}
The electrochemical behaviour of copper in borate buffers containing KSCN is studied by potentiostatic and potentiodynamic techniques complemented with scanning electron microscopy and EDAX. The voltammetric response can be divided into three regions. Region $I$ is related to the formation of a $\mathrm{Cu}(\mathrm{SCN})_{\mathrm{ad}}$ monolayer followed by a porous tridimensional growth of CuSCN(s). A complex oxide layer containing a $\mathrm{Cu}(\mathrm{I})$ inner and a $\mathrm{Cu}(\mathrm{II})$ outer layer is formed under the CuSCN layer leading to metal passivation. At this stage of the process soluble $\mathrm{Cu}$ (I) and $\mathrm{Cu}$ (II) species are detected. Region II corresponds to the onset of $\mathrm{Cu}$ passivity through the formation of a complex film. The passive region extends up to a certain critical value (breakdown potential) associated with the localized corrosion of base Cu (region III). The breakdown potential decreases linearly as the KSCN concentration increases. The localized corrosion process is apparently related to the nucleation and growth of an unstable $\mathrm{Cu}(\mathrm{SCN})_{2}$ layer in equilibrium with $\mathrm{Cu}(\mathrm{SCN})_{3}^{-}$(I). A reaction pathway is presented to account for the overall electrochemical behaviour of $\mathrm{Cu}$ in borate buffers containing $\mathrm{KSCN}$.
\end{abstract}

\section{INTRODUCTION}

Copper, as other metals, is used in many technical applications. In some cases copper is adequate to withstand corrosion for a long time while in others, such as copper electrometallurgy, it is important to accelerate the electrochemical reactions related to the copper electrode in acid solution[1-3]. The latter comprises copper electrowinning, copper electrorefining, the preparation of $\mathrm{Cu}_{2} \mathrm{O}$ and the formation of $\mathrm{CuO}$ layers. Despite this large number of applications of copper the data available related to corrosion and passivation and localized attack of copper in aqueous solutions is rather scarce as compared to those of other metals.

The anodization of $\mathrm{Cu}$ is a complex process which depends on many variables, such as solution composition, temperature, metal treatment, etc. In this respect, the formation of copper oxide layer in slightly alkaline solutions, involves many reactions yielding soluble $\mathrm{Cu}$ (I) species, hydrous $\mathrm{Cu}_{2} \mathrm{O}$, soluble $\mathrm{Cu}$ (II), hydrous $\mathrm{Cu}(\mathrm{OH})_{2}$, and the formation of $\mathrm{Cu}$ (III) species $[4,5,6]$. The anodic layer, in this case, likely comprises a complex structure involving hydrous $\mathrm{Cu}(\mathrm{I})$ species at the inner part and a hydrous Cu(II) species at the outer part[7]. This probably implies a composition profile in depth which is dependent on the anodic layer thickness.

It has been recently shown that the protective properties of the anodic layer containing $\mathrm{Cu}(\mathrm{I})$ and $\mathrm{Cu}$ (II) species can be modified in the presence of aggressive anions such as chloride and sulphide ions $[8,9]$. In this case the competing action of film forming species on $\mathrm{Cu}$ produces under certain circum-

* Present address: Laboratorio Electroquímica, Facultad de Química, Pontificia Universidad Católica de Chile. stances an enhancement of $\mathrm{Cu}$ electrodissolution as a localized corrosion of the base metal. These results are interesting in many aspects such as the theory of active-passive transition of metals, the modification of protective properties of passivating layers, the extension of knowled ge on localized corrosion of metals and the enhancement of the electrodissolution of $\mathrm{Cu}$ and Cu minerals.

The present paper, following the line of previous publications, refers to the dissolution, passivation and localized corrosion of $\mathrm{Cu}$ in aqueous solutions containing $\mathrm{KSCN}$ in the $\mathrm{pH}$ range from 8.8 to 11.5.

\section{EXPERIMENTAL}

Working electrodes (specimens) were made of polycrystalline 99.9 copper rods ( $3 \mathrm{~mm}$ dia.) axially embedded in Araldite holders to obtain circular exposed areas of $0.072 \mathrm{~cm}^{2}$ apparent area. The metal surface was firstly mechanically polished with fine grained emery paper followed with alumina paste $(0.3 \mu \mathrm{m}$ dia.) on polishing cloth. The polished specimen was rinsed with twice distilled water, and then dried in air at room temperature. A new pretreated specimen was used for each run. Measurements were made in a conventional Pyrex glass cell containing 0.2 l of electrolyte solution at $25 \pm 0.1^{\circ} \mathrm{C}$. The potential of the working electrode was measured against a saturated calomel electrode (sce) connected through two salt bridges filled with saturated $\mathrm{KNO}_{3}$ to avoid chloride diffusion into the cell and provided with a Luggin-Haber capillary tip to make contact with the electrolyte solution. A platinum plate was used as counter electrode. Potentials in the text are referred to the sce scale.

The electrolyte solution consisted of sodium borate-boric acid buffer at $\mathrm{pH}$ from 3.8 to 11.5 
containing variable amounts of $\mathrm{KSCN}[0.075 \mathrm{M}$ $\left.\mathrm{Na}_{2} \mathrm{~B}_{4} \mathrm{O}_{7}+0.15 \mathrm{M} \mathrm{H}_{3} \mathrm{BO}_{3}+x c_{\mathrm{KSCN}}(0<x<1 \mathrm{M})\right]$. It was prepared from A.R. chemicals and twice distilled water and was purged with purified nitrogen during $2 \mathrm{~h}$ previously to each run.

Singular triangular potential sweep (stps) voltammograms run between the cathodic $\left(E_{s, c}\right)$ and the anodic $\left(E_{s, \alpha}\right)$ switching potential at the sweep rates (v) $0.02,0.002$ and $0.0002 \mathrm{Vs}^{-1}$ were recorded in the conventional way and presented as apparent current density $(j)$ vs potential $(E)$ plots. Prior to each run, the specimen was held at $-1.00 \mathrm{~V}$ in the solution during $90 \mathrm{~s}$ to achieve a reproducible initial electroreduced copper surface.

The ring-disc technique ( $r$ rde) was used to detect soluble $\mathrm{Cu}$ ionic species formed during the electrooxidation of $\mathrm{Cu}$ to either $\mathrm{Cu}(\mathrm{I})$ or $\mathrm{Cu}(\mathrm{II})$. For this purpose an $\mathrm{Au}$ ring $\left(0.035 \mathrm{~cm}^{2}\right.$ apparent area) $\mathrm{Cu}$ disc $\left(0.125 \mathrm{~cm}^{2}\right.$ apparent area) rotating electrode was used (collection efficiency 0.25 ) at rotation speeds $(\omega)$ in the $250 \leqq \omega \leqq 3000$ rpm range. Current transients $(I / t)$ at constant potential $\left(E_{s}\right)$ were also recorded covering different ranges of potential. In this case, preceding the application of the potential stcp at $E_{s}$, the working electrode was held firstly at $-1.2 \mathrm{~V}\left(E_{c}\right)$ during $90 \mathrm{~s}$, and later at $-0.30 \mathrm{~V}\left(E_{a}\right)$ during another $90 \mathrm{~s}$ to form a prepassive layer. Complementary SEM observations and EDAX data were also obtained from a Philips 500 equipment.

\section{RESULTS}

\section{Voltammetric data}

The initial single triangular potential sweep at $0.02 \mathrm{~V} \mathrm{~s}^{-1}$ between $E_{s, \mathrm{c}}=-1.00 \mathrm{~V}$ and $E_{s, a}=0.80 \mathrm{~V}$ in the plain borax buffer shows four anodic current contributions (Fig. 1a), namely one located at $-030 \mathrm{~V}$ $\left(A_{I I}\right.$ ), at $-0.06 \mathrm{~V}$ (peak $A_{I I}$ ), at $0.0 \mathrm{~V}$ (shoulder $A_{I I I}$ ) and a broad peak at $0.50 \mathrm{~V}\left(\mathrm{~A}_{\mathrm{III}}\right)$. The returning potential șcan presents three cathodic contributions at $-0.25 \mathrm{~V}$ (peak $\mathrm{C}_{\mathrm{II}}$ ), at $-0.44 \mathrm{~V}$ (peak $\mathrm{C}_{\mathrm{II}}$ ) and a shoulder $\left(\mathrm{C}_{\mathrm{II}}\right)$ at $\mathrm{ca}-0.5 \mathrm{~V}$. Peaks $\mathrm{A}_{\mathrm{II}}$ and $\mathrm{A}_{\mathrm{II}}$ are assigned to the electroformation of $\mathrm{CuOH}_{\mathrm{ad}}$ species and $\mathrm{Cu}_{2} \mathrm{O}$ hydrated layer, respectively, while peaks $A_{111}$ and $\mathrm{A}_{\text {III }}$ are related to the electroformation of either $\mathrm{CuO}$ or $\mathrm{Cu}(\mathrm{OH})_{2}[4,5]$. ESCA and ISS data indicate that the passive film consists of an inner $\mathrm{Cu}_{2} \mathrm{O}$ layer and outer $\mathrm{CuO}$ or $\mathrm{Cu}(\mathrm{OH})_{2}$ layer[7]. This complex structured film is electroreduced in two consecutive
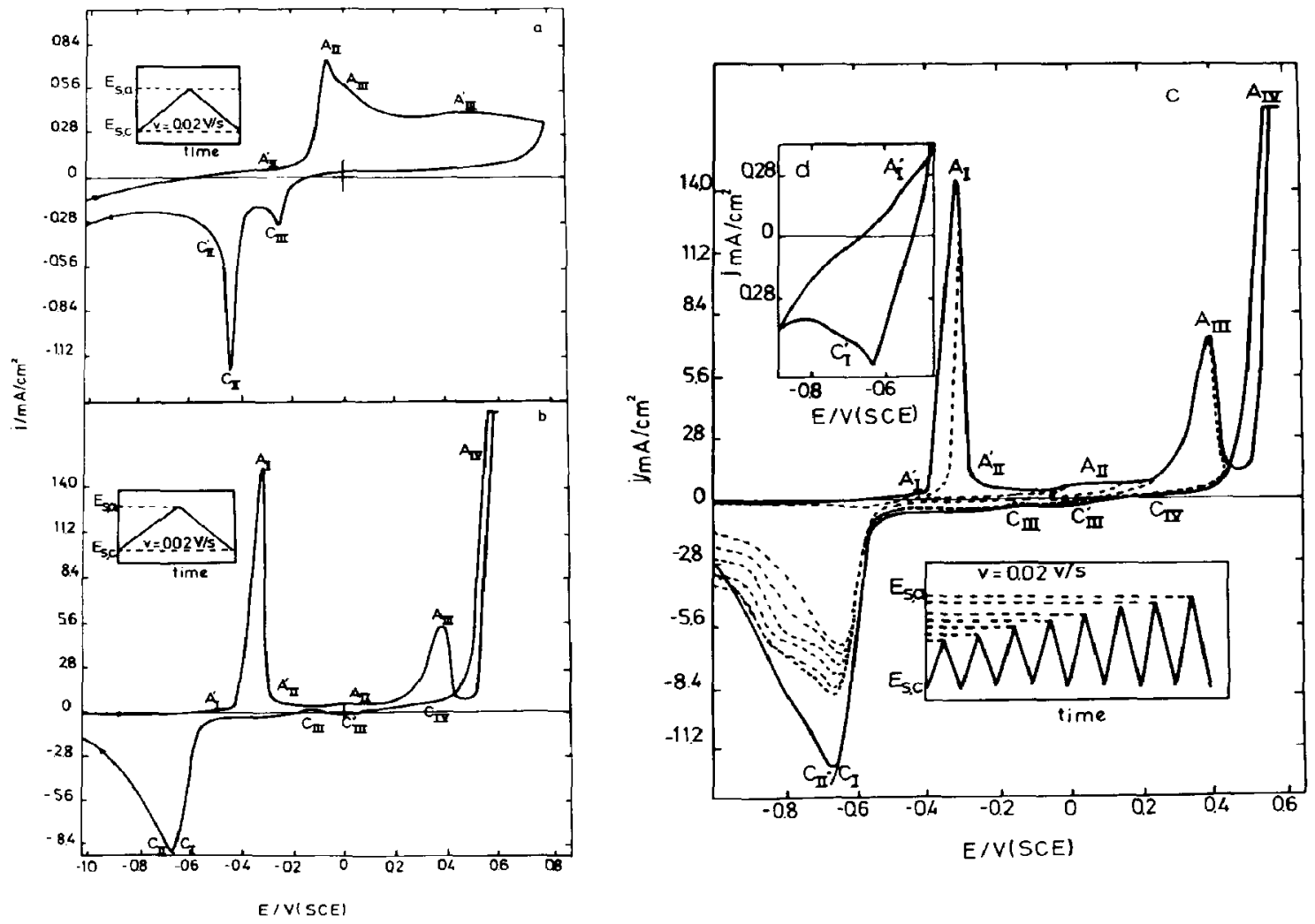

Fig. 1. Voltammograms of copper at $0.02 \mathrm{Vs}^{-1}, T=25^{\circ} \mathrm{C}$. (a) STPS in borax buffer; (b) STPS in borax buffer + $0.2 \mathrm{M} \mathrm{KSCN}$; (c) stabilized voltammograms in borax buffer $+0.2 \mathrm{M} \mathrm{KSCN}$; (d) detail of the stahilized voltammograms at the negative side of current peak $A_{I}$. 
steps to $\mathrm{Cu}(\mathrm{I})$ and $\mathrm{Cu}(0)$ in the potential range of $\mathrm{C}_{\mathrm{III}}$ and $C_{I I}$, respectively [7].

Similar runs made in borax buffer containing $0.2 \mathrm{M}$ KSCN show a complex $E / j$ profile (Fig. 1b) which exhibits in the positive-going scan, six anodic current contributions, namely, at $-0.50 \mathrm{~V}\left(\mathrm{~A}_{\mathrm{I}^{\prime}}\right)$, at $-0.32 \mathrm{~V}$ (peak $A_{I}$ ), at $-0.28 \mathrm{~V}$ (shoulder $A_{I I}$ ), at $0.0 \mathrm{~V}$ a small broad peak $\left(A_{I I}\right)$ and at $0.39 \mathrm{~V}$ (peak $A_{I I I}$ ).

At potentials more positive than $A_{1 I I}$ a small passive region is observed and when the potential exceeds a certain critical value $\left(E_{b}\right)$ a remarkable current increase is recorded $\left(A_{1 V}\right)$. Likewise, the returning potential scan presents at least four processes which can be characterized as follows: at $0.35 \mathrm{~V}\left(\mathrm{C}_{\mathrm{IV}}\right)$, at $0.0 \mathrm{~V}\left(\mathrm{C}_{\mathrm{IV}}\right)$, at $c a-0.120 \mathrm{~V}$ a small anodic peak $\left(\mathrm{C}_{\mathrm{III}}\right)$ and at $-0.68 \mathrm{~V}$ an asymmetric cathodic peak (peak $C_{1} / C_{I I}$ ).

The inspection of the voltammogram resulting when $E_{s, c}$ is set at $-1.0 \mathrm{~V}$ and $E_{s, a}$ is stepwise incrcased from -0.45 to $0.60 \mathrm{~V}$ (Fig. 1c) shows the following facts: the current at $A_{I}$ is related to current peak $C_{I}$ included in the complex peak $C_{1} / C_{1 I}$; the species electroformed in the potential range $A_{I I}$ and $A_{I I}$ are electroreduced in the potential range of $C_{I I}$; current peak $A_{I I I}$ is associated with current peaks $\mathrm{C}_{\mathrm{III}}, \mathrm{C}_{\mathrm{III}}$ and it contributes to increase the charge associated with $\mathrm{C}_{\mathrm{II}}$. Moreover, a more detailed voltammogram run in the potential range between -1.0 and $-0.50 \mathrm{~V}$ (Fig. 1d) shows that current at $A_{I}$ is related to peak $C_{I}$. The charge density involved in $A_{I^{\prime}}$ is roughly estimated as $0.1-0.2 \mathrm{mC} \mathrm{cm}^{-2}$ apparent area.

In the borax buffer containing KSCN, the current contributions $A_{1 I}$ and $A_{I I}$, assigned to the electroformation of the $\mathrm{Cu}_{2} \mathrm{O}$ layer, are preceded by the formation of $[\mathrm{CuSCN}]_{\text {ad }}$ species (current $A_{I^{\prime}}$ ) and [CuSCN](s) (peak $\mathrm{A}_{\mathrm{I}}$ ). The $\mathrm{Cu}_{2} \mathrm{O}$ layer yields the complex passive film [inner $\mathrm{Cu}_{2} \mathrm{O}$ and outer $\mathrm{CuO}$ or $\mathrm{Cu}(\mathrm{OH})_{2}$ ] at current peak $A_{I I I}$. However, in the presence of $\mathrm{KSCN}$ the oxide formation shifts towards potentials more positive than those observed for the plain buffer. Furthermore, the same potential shift is observed for the electroreduction of the Cu(II) oxide species to $\mathrm{Cu}(\mathrm{I})$ (peaks $\mathrm{C}_{\mathrm{III}}$ and $\mathrm{C}_{\mathrm{III}}$ ). These results suggest that copper oxide electroformation is hindered in the presence of KSCN, but the electroreduction of $\mathrm{Cu}(\mathrm{I})$ oxide species occurs at potentials more negative than in the plain buffer probably due to the presence of the [CuSCN](s) film formed at $A_{I}$.

After $A_{I I I}$, when the oxide film is completed, $\mathrm{Cu}$ passivation sets in. Then, when the applied potential exceeds $E_{b}$, passivity breakdown and pitting corrosion of the base metal is observed. The increase in area caused by pitting reflects in the hysteresis of the voltammogram at the initial portion of the returning scan. The breakdown potential (pitting potential) $\left(E_{b}\right)$ is estimated from voltammograms run at low sweep rates $\left(0.002\right.$ and $\left.0.0002 \mathrm{~V} \mathrm{~s}^{-1}\right)$ in the borax buffer containing different concentrations of KSCN (Fig. 2). In these voltammograms peak $A_{j}$ is very sharp and its potential $\left(E_{A_{1}}\right)$ is close to the equilibrium potential of the $\mathrm{Cu} / \mathrm{CuSCN}(\mathrm{s}) / \mathrm{SCN}^{-}$system. The increase in $c_{K S C N}$ moves $E_{A_{F}}$ towards more negative values and also produces an increase in current associated with $A_{1}$ and $A_{\text {III. }}$ Correspondingly, peak $A_{\text {III }}$ at the positive potential side of peak $A_{\text {III }}$ begins to develop, the corresponding peak potentials shift towards more positive values, and $E_{b}$ moves in the negative direction

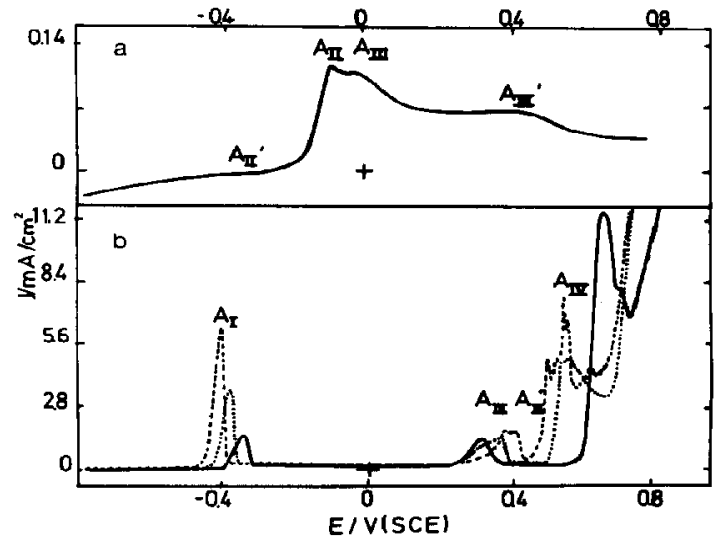

Fig. 2. Voltammograms of copper at $0.002 \mathrm{~V} \mathrm{~s}^{-1}, T=25^{\circ} \mathrm{C}$. (a) Borax buffer; (b) borax buffer $+0.1 \mathrm{M} \mathrm{KSCN}(-)$ borax buffer $+0.25 \mathrm{M} \mathrm{KSCN}(\cdots)$, borax buffer $+0.5 \mathrm{M}$ KSCN $(---)$.

so that the actual passive region becomes smaller. From these runs reasonable linear $E_{b} v s \log c_{\mathrm{KSCN}}$ plots are obtained, the slope of which depends on $v$ (Fig. 3a). Thus, at $0.0002 \mathrm{Vs}^{-1}$ the slope is close to $0.40 \mathrm{~V}$ decade ${ }^{-1}$ and at $0.002 \mathrm{Vs}^{-1}$ it is $0.18 \mathrm{~V}$ decade ${ }^{-1}$. Therefore, at a constant $c_{\mathrm{KSCN}}$, as $v$ increases $E_{b}$ decreases. These results are not surprising if a more stable passive film is formed at low $v$. Moreover, at a constant $c_{\mathrm{KSCN}}, E_{b}$ becomes more positive as the $\mathrm{pH}$ of the solution increases. A linear $E_{b} / \log \mathrm{pH}$ plot with a slope very close to $2.3 R T / F \mathrm{~V}$ decade ${ }^{-1}$ is obtained at $v=0.002 \mathrm{~V} \mathrm{~s}^{-1}$ (Fig. 4). The increase in $\mathrm{pH}$ decreases the height of peak $A_{\text {III }}$ and shifts $E_{\mathrm{A}_{\text {III }}}$ towards more negative values.

Peak $A_{1 V}$ is closely associated with the pitting process (Fig. 2) as revealed by using $c_{\mathrm{KSCN}}$ lower than $0.3 \mathrm{M}$. Otherwise at $c_{\mathrm{KSCN}}>0.3 \mathrm{M}$ peak $\mathrm{A}_{\mathrm{IV}}$ is not

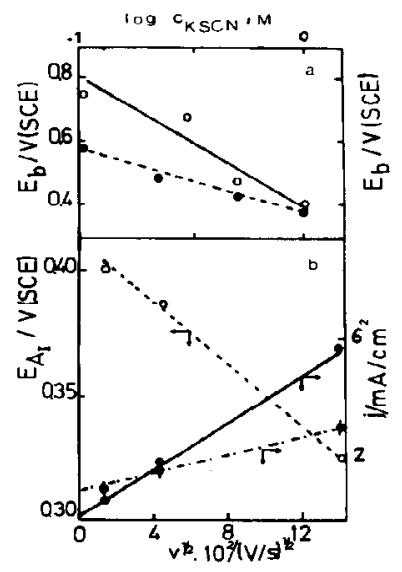

Fig. 3. (a) $E_{\mathrm{b}}$ vs $\log$ concentration of $\mathrm{KSCN}$ plot (-) $0.002 \mathrm{Vs} \mathrm{s}^{-1} ;\left(\stackrel{\longrightarrow}{\longrightarrow} 0.0002 \mathrm{Vs}^{-1}\right.$. (b) $E_{\mathrm{A}_{1}}$ os $v^{1 / 2}$ plot $(---), j_{\mathrm{A}_{\mathrm{I}}}$
vs $v^{1 / 2}$ plot $(--), j_{\mathrm{A}_{\mathrm{II}}}$ es $v^{1 / 2}$ plot $(-\cdot-\cdot)$. 


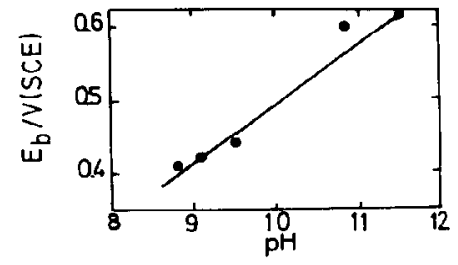

Fig. 4. $E_{b}$ vs $\mathrm{pH}$ plot $\left(c_{\mathrm{KSCN}}=0.5 \mathrm{M}\right), 0.002 \mathrm{Vs}^{-1}$.

clearly observed because in this case strong current oscillations associated with pitting occurs.

The height of both peaks $A_{I}$ and $A_{I I I}$ depends linearly on $v^{1 / 2}$, although the straight line corresponding to peak $A_{\text {III }}$ does not go through the origin of coordinates (Fig. 3b). A similar relation was observed for $E_{A_{1}}$ (Fig. 3b).

At a constant $c_{\mathrm{KSCN}}$, there is only a slight increase in the height of peak $A_{I}$ on increasing $\omega$, the corresponding charge being independent of $\omega$ (Fig. 5a). Conversely, the height of peak $A_{\text {III }}$ and the corresponding charge density $\left(q_{A_{I I I}}\right)$ increases aocordingly to $\omega$ (Fig. $5 b$ and c). Furthermore, rotation moves the pitting process towards more positive potentials. No influence of $\omega$ on the height and charge of peak $\mathrm{A}_{\mathrm{III}}$ is noticed (Fig. 5a).

When $E_{s, a}$ is set more positive than the potential of peak $A_{\text {III }}$ but sufficiently small to prevent pitting, the negative potential going scan shows another anodic current (shoulder $A_{I^{\prime \prime}}$, Fig. 6a) which is comparable to $A_{\text {III' }}$ (Fig. 6c). Shoulder $A_{1 I^{\prime \prime}}$ is followed by a very sharp anodic peak and finally, the current decreases to reach

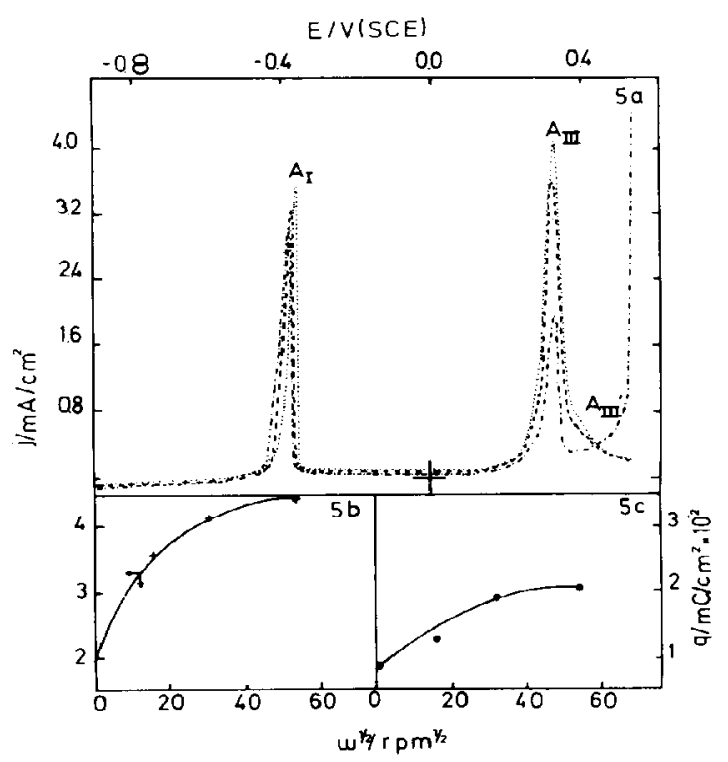

Fig. 5. (a) Voltammograms of a copper rotating disc electrode in borax buffer $+0.3 \mathrm{M}$ KSCN: $\omega=0\left(-\cdot \cdot_{-} \cdot\right)$, $\omega$ $=250(--), \omega=3000(\cdots), T=25^{\circ} \mathrm{C}$. (b) $j_{\mathrm{A}_{\mathrm{II}}}$ vs $\omega^{1 / 2}$ plot. (c) $q$ vs $\omega^{1 / 2}$ plot, $T=25^{\circ} \mathrm{C}$.

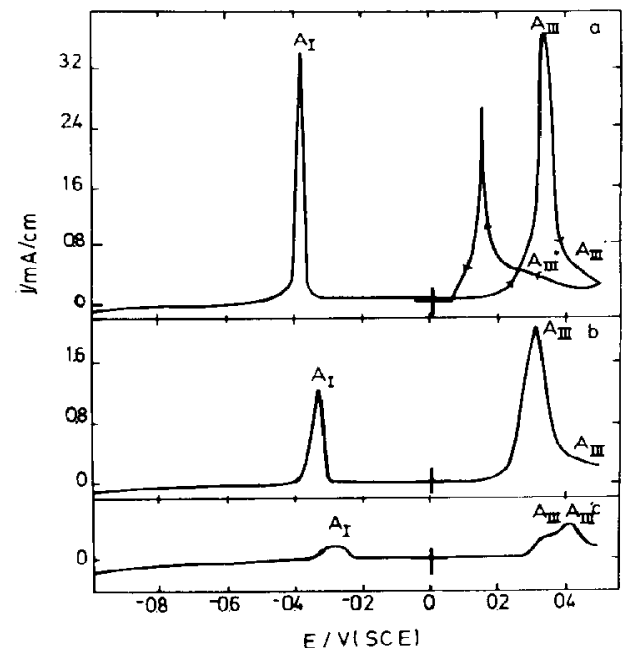

Fig. 6. Voltammograms of a copper rotating disc electrode in borax buffer containing (a) $0.3 \mathrm{MKSCN}$; (b) $0.1 \mathrm{M} \mathrm{KSCN}$; (c) $0.01 \mathrm{M} \mathrm{KSCN} ; T=25^{\circ} \mathrm{C}$.

the small value of the baseline voltammogram. At constant $\omega$, the increase in $c_{\mathrm{KSCN}}$ moves $E_{\mathrm{A}_{1}}$ towards more negative values and increases the current associated with both $A_{1}$ and $A_{1 I I}$ (Fig. 6). The following parametric relationships are obtained from these voltammetric runs (Fig. 7a, b, c, d); a linear $E_{\mathrm{A}_{1}} v s \log c_{\mathrm{KSCN}}$ plot with a slope close to $2.3 R T / F \vee$ decade $^{-1}$; a linear $j_{\mathrm{A}_{1}}$ vs $c_{\mathrm{KSCN}}$ plot; a linear $j_{(E=0.0 \mathrm{v})}$ vs $c_{\mathrm{KSCN}}$ plot and a linear $j_{\mathrm{A}_{\text {III }}}$ os $c_{\mathrm{KSCN}}$ plot.

\section{Rotating ring disc electrode data}

Data were also obtained from the rrde technique by applying to the disc a potential sweep at $0.002 \mathrm{~V} \mathrm{~s}^{-1}$ and holding the potential in the ring at $-0.80 \mathrm{~V}$ to electroreduce the $\mathrm{Cu}(\mathrm{I})$ and $\mathrm{Cu}(\mathrm{II})$ soluble species produced during the voltammetric scan at the disc. Rrde data are consistent with the presence of soluble Cu species at potentials corresponding to the potential ranges of peaks $A_{I^{\prime}}, A_{I}$ and $A_{I I I}$ (Fig. 8). Similar experiments were made to detect only soluble $\mathrm{Cu}(\mathrm{I})$ species by holding the potential in the ring at $+0.3 \mathrm{~V}$ where $\mathrm{Cu}(\mathrm{I})$ is oxidized to $\mathrm{Cu}(\mathrm{II})$. Soluble $\mathrm{Cu}(\mathrm{I})$ species are detected in the potential range $A_{I} / A_{I}$ and to a smaller extent at potentials of peak $A_{111}$. Rrde results suggest that the $\mathrm{Cu}$ electrodissolution within the potential $A_{I I}$ is mainly due to soluble Cu(II) species. In this case the ring current at constant $\omega$ approaches a linear dependence on $c_{\mathrm{KSCN}}$ (Fig. 9). Otherwise, the ring current detected at $A_{I^{\prime}}$ and $A_{I}$ increases linearly with the square of $c_{\mathrm{KSCN}}$ (Fig. 9). The increase of $\omega$ results in the increase of the ring current in the $A_{r}$ and $A_{1}$ range but produces a remarkable reverse effect in the $A_{\text {III }}$ range.

\section{Current transients under a constant potential step}

Current transients under a constant potential step $\left(E_{s}\right)$ in the borax buffer $+0.3 \mathrm{M} \mathrm{KSCN}$ were obtained by the following procedure. The electrode was firstly 


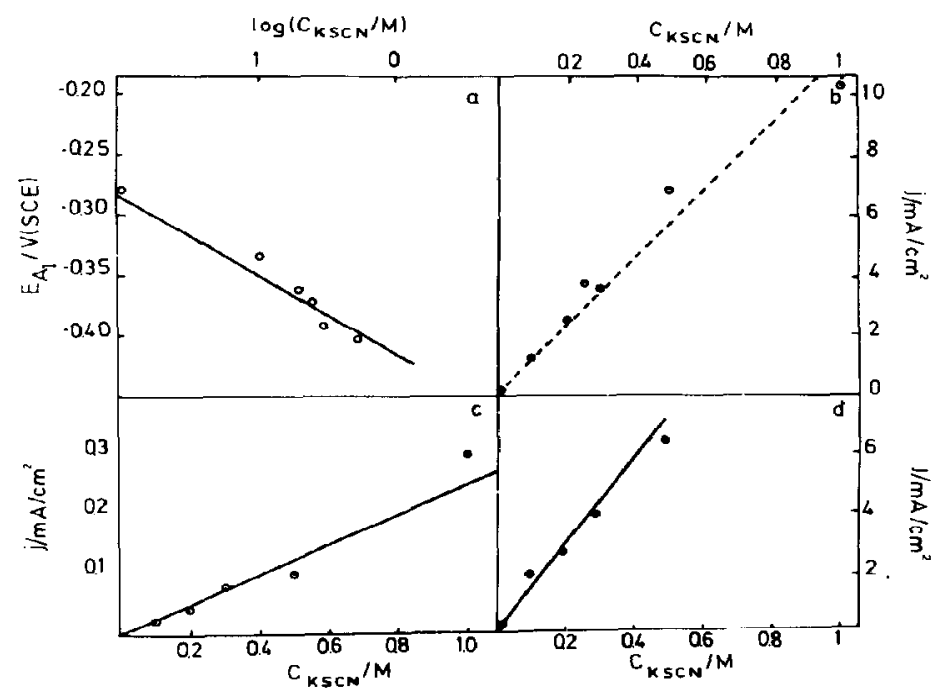

Fig. 7. (a) $E_{\mathrm{A}_{\mathrm{I}}}$ vs $\log c_{\mathrm{KSCN}}$ plot, (b) $j_{\mathrm{A}_{\mathrm{I}}}$ is $c_{\mathrm{KSCN}}$ plot, (c) $j\left(E=0.0 \mathrm{~V}\right.$ ) $v s c_{\mathrm{KSCN}}$ plot, (d) $j_{\mathrm{A}_{\mathrm{III}}} v s c_{\mathrm{KSCN}}$ plot.

held at $-1.20 \mathrm{~V}$ during $90 \mathrm{~s}$ to electroreduce the $\mathrm{Cu}$ surface and immediately afterwards stepped to $-0.30 \mathrm{~V}$ during another $90 \mathrm{~s}$ to form the prepassive layer which includes the species formed at $A_{1}$ and $A_{1 I^{*}}$. Immediately afterwards the electrode was stepped to $E_{s}$ and the corresponding current transient simultaneously recorded. In the $-0.30 \mathrm{~V}<E_{\mathrm{s}}<0.0 \mathrm{~V}$

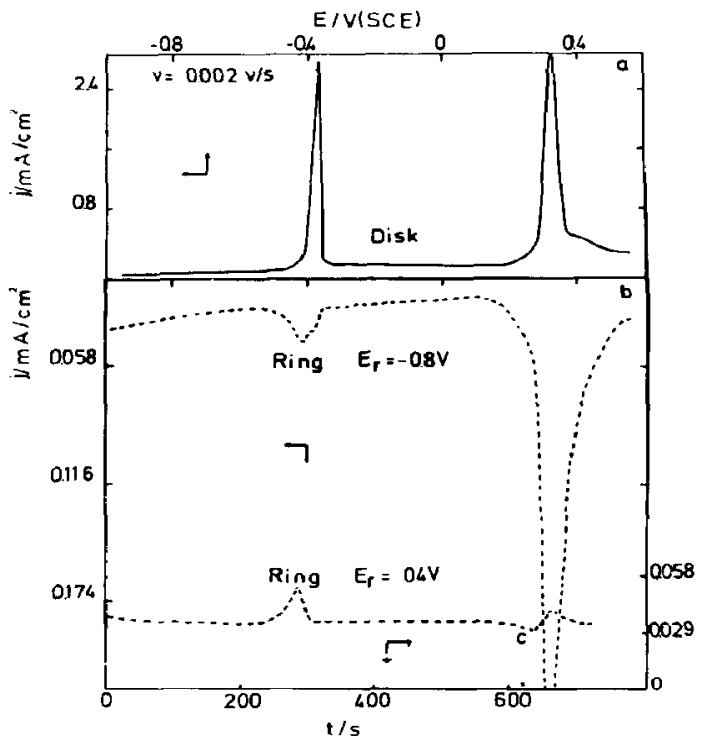

Fig. 8. (a) Voltammgrams of a copper rotating disc electrode at $0.002 \mathrm{~V} \mathrm{~s}^{-1}$ in borax buffer $+0.3 \mathrm{M} \mathrm{KSCN}, \omega=250, T$ $=25^{\circ} \mathrm{C}$. (b) Current density at the ring electrode, $E_{\text {, }}=$ $-0.80 \mathrm{~V}$. (c) Current density at the ring electrode, $E_{r}=0.40 \mathrm{~V}$. range the current initially decreases but later it defines a coarse hump which is related in part to the completion of the $\mathrm{Cu}_{2} \mathrm{O}$ film and in part to the electrodissolution of $\mathrm{Cu}$ as soluble $\mathrm{Cu}(\mathrm{I})$. On the other hand, current transients in the $0.0 \mathrm{~V}<E_{s}<0.20 \mathrm{~V}$ range exhibit a continuous current decrease to attain a stationary value which is independent of $\omega$ (see Fig. 5a). When $E_{s}>0.20 \mathrm{~V}$, the current initially decreases to a minimum $\left(I_{m}\right)$ and after a certain time it rises to attain a maximum $\left(I_{M}\right)$ at $t_{M}$ (Fig. 10a). This current peak is associated with current peak $A_{I I I}$ and it contains the contribution of the $\mathrm{CuO}$ or $\mathrm{Cu}(\mathrm{OH})_{2}$ electroformation and that of the strong copper electrodissolution as soluble $\mathrm{Cu}(\mathrm{II})$ as detected by the rrde techniques. Finally, the current decreases to a minimum and after a certain time $\left(t_{i}\right)$ it increases to attain a constant value

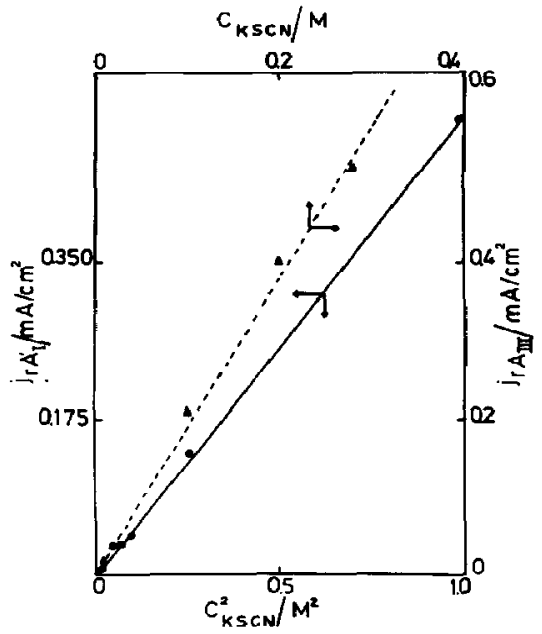

Fig. 9. $j_{r\left(\Lambda_{1}\right)}$ vs $c_{\mathrm{KSCN}}^{2}(-)$ and $j_{r\left(\Lambda_{\mathrm{II}}\right)}$ us $c_{\mathrm{KSCN}}(--)$ plots. 

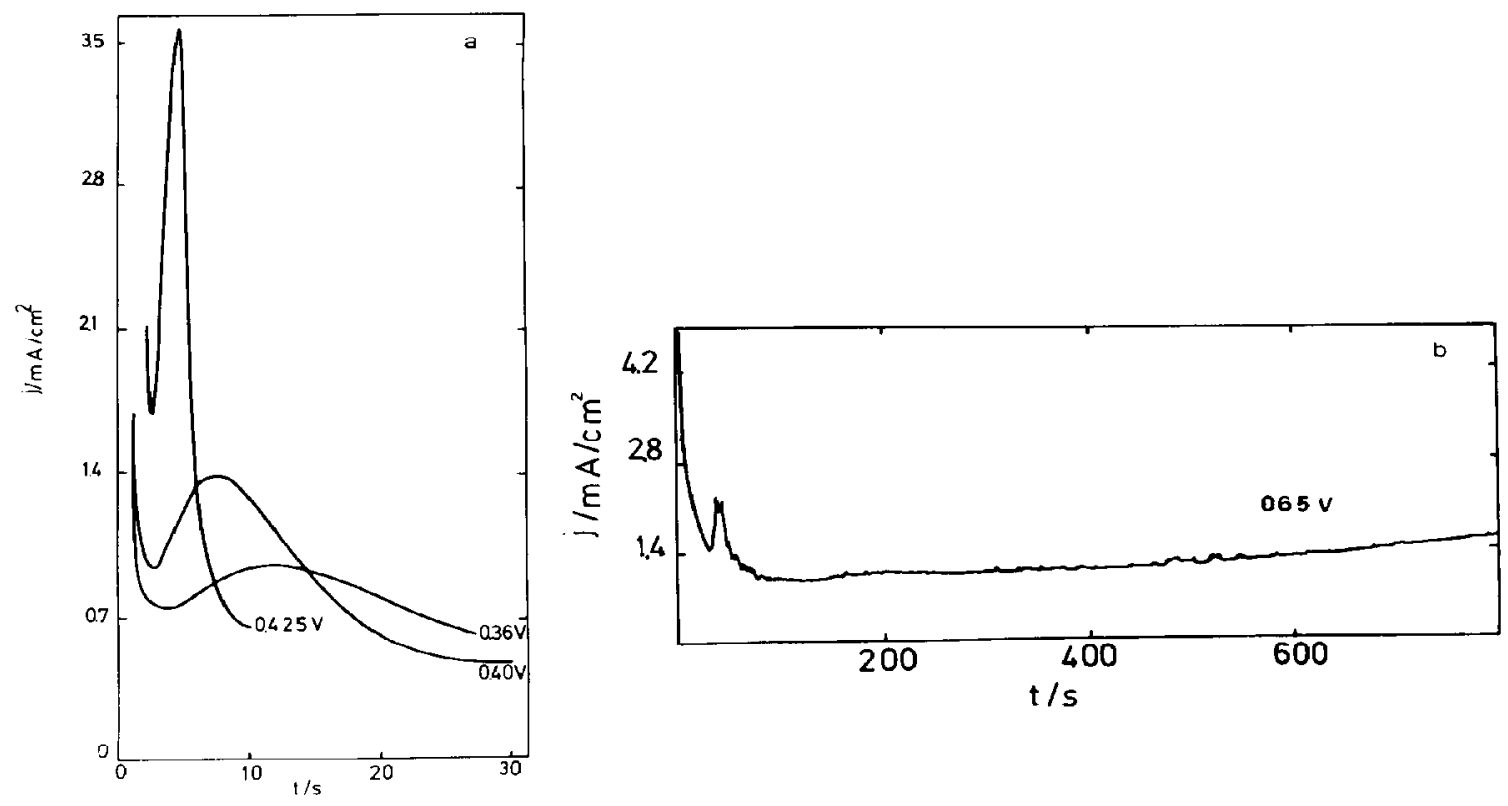

Fig. 10. (a) Current transients at constant potential, (a) borax buffer $+0.3 \mathrm{M} \mathrm{KSCN}$; (b) borax buffer $+0.5 \mathrm{M} \mathrm{KSCN}$.

(Fig. 10b). Random oscillations associated with the copper pitting are observed in this portion of the current transient.

The increase in $E_{s}$ results in the increase of $I_{M}$ and the decrease of $t_{M}$. Likewise, the increase of $E_{s}$ in the pitting region produces a decrease in $t_{i}$ and a rapid increase of the pitting current. The apparent pitting current density follows the relationship (Fig. 11):

$$
\left(j-j_{c}\right)=k\left(t-t_{i}\right)^{b}
$$

where $j$ and $j_{c}$ are the overall and the background current densities respectively, and $k$ and $b$ are constants $(b \simeq 1.5)$. It comes out that under potentiostatic conditions pitting starts at potentials lower than those obtained from the voltammogram.

\section{$S E M$ patterns and EDAX data}

Macroscopic observations of $\mathrm{Cu}$ electrodes held at $0.0 \mathrm{~V}$ during $30 \mathrm{~min}$ in the borax buffer $+0.3 \mathrm{M}$

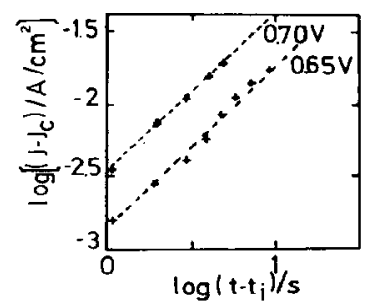

Fig. 11. $\log \left(j-j_{c}\right)$ vs $\log \left(t-t_{i}\right)$ plots. Electrolyte: borax buffer $+0.5 \mathrm{M}$ KSCN.
KSCN reveal the presence of a thick white layer, which according to SEM observations consists of a large number of small crystals (Fig. 12). EDAX and electron microprobe analysis demonstrate the white layer contains $\mathrm{S}, \mathrm{Cu}$ and $\mathrm{N}$. Semi-quantitative data confirm that at $E_{s}<E_{\mathrm{A}_{\mathrm{II}}}$ the white layer approaches the formula CuSCN.

When the electrode is anodized at $0.325 \mathrm{~V}$ during $30 \mathrm{~min}$ in the borax buffer $+0.3 \mathrm{M} \mathrm{KSCN}$, black spots are initially formed on the copper surface. The electrode becomes covered with a black film when it is held in the solution at $0.325 \mathrm{~V}$. However, under open circuit the black film turns instantaneously into a white film. SEM observations also show that this white film presents a large number of randomly distributed holes (Fig. 13a and $b$ ), and on average it is thinner than that obtained at $0.0 \mathrm{~V}$, as determined through the EDAX sulphur signal. In this case, the removal of corrosion products leaves a copper surface which exhibits a localized corrosion (Fig. 14a and b).

\section{DISCUSSION}

The anodic polarization of polycrystalline copper in borax buffer containing $\mathrm{KSCN}$ results in a complex current response which can be arbitrarily divided into three potential regions for a rational discussion of results. Region $I$ is comprised in the $E_{A_{I^{\prime}}}<E_{s}<E_{A_{I I}}$ potential range and it is related to the electroformation of the CuSCN layer followed by the early stages of the hydrous cuprous oxide/hydrous cupric oxide film, Region II lies in the $E_{\Lambda_{I I I}}<E_{s}<E_{b}$ range where passivity sets in. Finally, region III, extending for $E_{s}>E_{b}$ corresponds to the rupture of the passive layer 


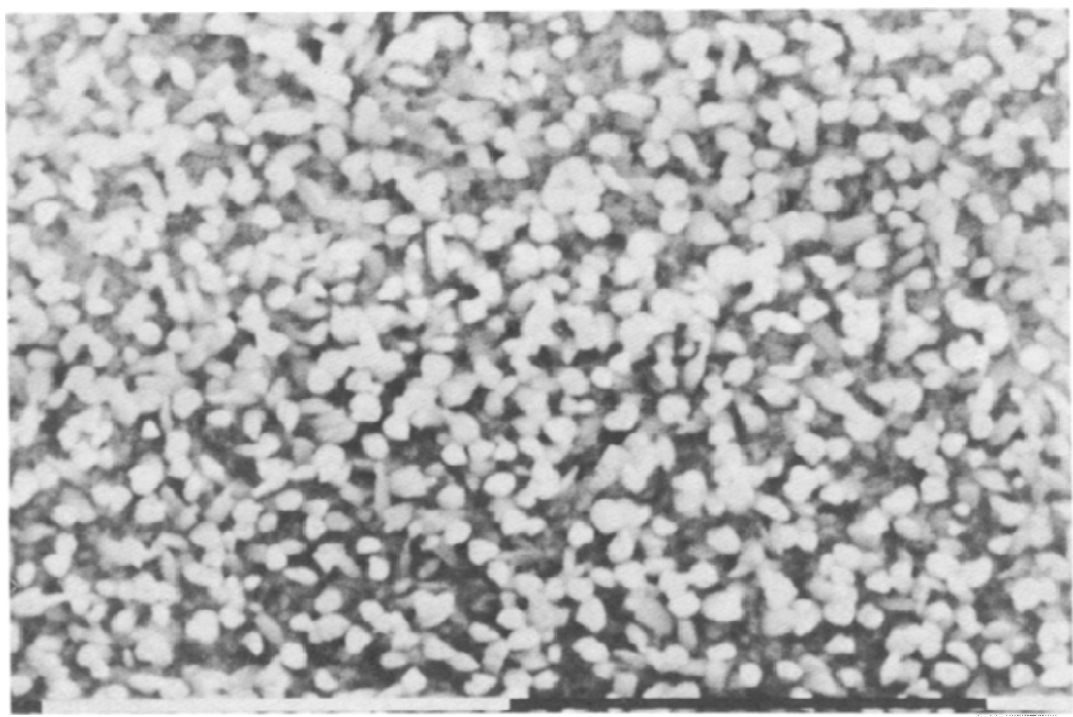

Fig. 12. SEM microphotograph of the copper electrode surface after anodizing at $0.0 \mathrm{~V}$ for $30 \mathrm{~min}$ in the borax buffer $+0.3 \mathrm{M}$ KSCN . Scale: $10 \mu \mathrm{m}$.

and pitting corrosion of copper. In general, the voltammetric response of copper in KSCN containing solutions is seemingly comparable to that recently described for copper in the same electrolyte containing $\mathrm{NaCl}[9]$. This is not surprising as $\mathrm{SCN}^{-}$is isoelectronic with $\mathrm{Cl}^{-}$anion and their solvodynamic radii are very close.

\section{Reactions related to region $I$}

The first product detected in the anodization of copper in the borax buffer containing KSCN is CuSCN which appears as a crystalline white product. Its formation is responsible for the voltammetric peak $A_{I}$ which appears at a potential value very close to the equilibrium potential of the reaction $\left[E_{r} / \mathrm{V}(\right.$ sce $)=$ $-0.512 \mathrm{~V}]$

$$
\mathrm{Cu}+\mathrm{SCN}^{-}=\operatorname{CuSCN}(\mathrm{s})+e^{-} .
$$

The overall reaction (2) involves a previous step related to the hump appearing at the positive side of current peak $A_{I}$ (hump $A_{I^{\prime}}$ ) which involves a small charge density in the order of a single monolayer. As it occurs for halide ions it is reasonable to assume that reaction (2) occurs through adsorbed intermediates in a series of reactions:

$$
\begin{aligned}
\mathrm{Cu}+\mathrm{SCN}^{-} & =\mathrm{Cu}\left(\mathrm{SCN}^{-}\right)_{\mathrm{ad}} \\
\mathrm{Cu}\left(\mathrm{SCN}^{-}\right)_{\mathrm{ad}} & =\mathrm{Cu}(\mathrm{SCN})_{\mathrm{ad}}+e^{-} \\
{\left[\mathrm{Cu}(\mathrm{SCN})_{\mathrm{ad}}\right]_{n} } & =n \mathrm{CuSCN}(\mathrm{s})
\end{aligned}
$$

where the parentheses denote adsorbed species and $s$ distinguishes the formation of the new phase. This reaction is however more complex as soluble Cu(I) species are detected in this potential range through the rrde experiments. This can be accounted for by the copper complexing properties of halide and pseudohalides ions. Thus, before the concentration of $\mathrm{SCN}^{-}$ ions at the interface is depleted, soluble Cu(I) complex should result through the following equilibria:

$$
\begin{aligned}
\mathrm{Cu}(\mathrm{SCN})_{\mathrm{ad}}+2 \mathrm{SCN}^{-}= & \mathrm{Cu}(\mathrm{SCN})_{3}^{2-} \rightleftharpoons \mathrm{CuSCN}(\mathrm{s}) \\
& +2 \mathrm{SCN}^{-} .
\end{aligned}
$$

Reaction $2 b$ in the reverse direction is revealed by the voltammetric scan run in the negative potential going direction, through the charge contribution at $-0.63 \mathrm{~V}$ (Fig. 1d). The linear dependence of the height of peak $A_{1}$ and its potential on $v^{1 / 2}$ as well as the very slight dependence of peak current on $\omega$, indicates that the electroformation of the tridimensional thick CuSCN(s) layer is mainly under ohmic control.

When the applied potential exceeds that of the peak $A_{1}$, the depletion of $\mathrm{SCN}^{-}$ion concentration at the copper surface allows the formation of oxide species. The initiation of the anodic layer formation (peak $A_{\text {II }}$ ) implies a competitive metal interaction with water and $\mathrm{SCN}^{-}$which can be explained as follows

$$
\begin{aligned}
\mathrm{Cu}\left(\mathrm{SCN}^{-}\right)_{\mathrm{ad}}+\mathrm{H}_{2} \mathrm{O} & =\mathrm{Cu}\left(\mathrm{H}_{2} \mathrm{O}\right)_{\mathrm{ad}}+\mathrm{SCN}^{-} \\
\mathrm{Cu}\left(\mathrm{H}_{2} \mathrm{O}\right)_{\mathrm{ad}} & =\mathrm{Cu}(\mathrm{OH})_{\mathrm{ad}}+\mathrm{H}^{+}+e^{-} \\
x \mathrm{Cu}(\mathrm{OH})_{\mathrm{ad}} & \rightarrow x^{\prime} \mathrm{Cu}_{2} \mathrm{O} \text { (hydrous). }
\end{aligned}
$$

Reactions (3a)-(3c) are part of the complex mechanism of hydrous cuprous oxide formation recently discussed in detail both in strong and weakly alkaline solutions $[5,11,12]$. The anodic $\mathrm{Cu}_{2} \mathrm{O}$ layer grows just on the metal surface which is already covered with the crystalline CuSCN layer. At more positive potentials (peak $A_{1 I I}$ ) the electrooxidation of $\mathrm{Cu}_{2} \mathrm{O}$ to $\mathrm{Cu}(\mathrm{OH})_{2}$ takes place; this reaction probably occurs through the electrooxidation of $\mathrm{Cu}$ to soluble $\mathrm{Cu}(\mathrm{II})$ species as the latter is detected using the rrde technique in the potential range of peak $A_{111}$. The formation of soluble $\mathrm{Cu}(\mathrm{II})$ is easy to explain through the formation of a 

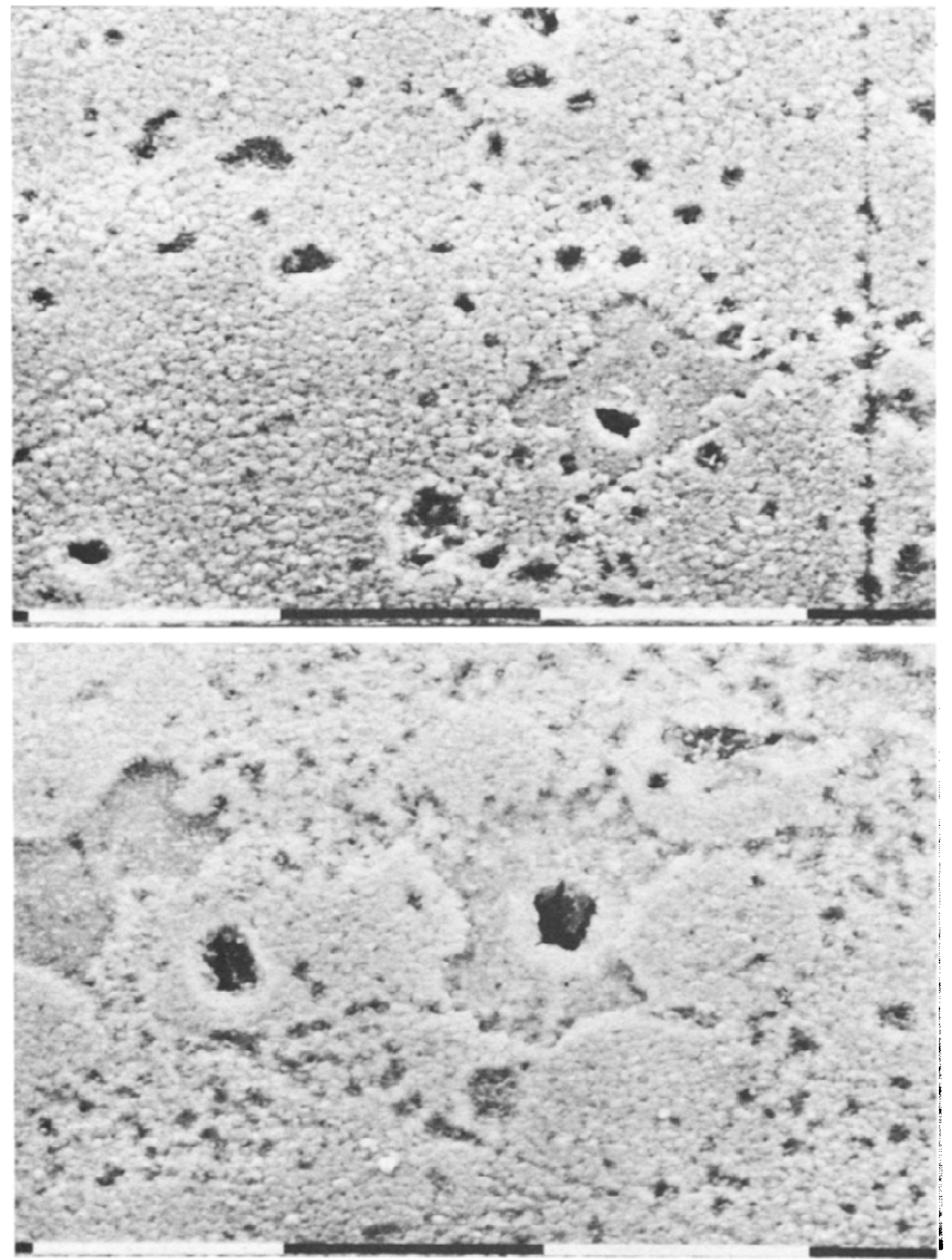

Fig. 13. SEM microphotographs of the copper electrode surface after anodizing at $0.325 \mathrm{~V}$ for 30 min in the borax buffer $+0.3 \mathrm{M} \mathrm{KSCN}$. Scale $10 \mu \mathrm{m}$.

complex ion as follows:

$$
\mathrm{Cu}+3 \mathrm{SCN}^{-}=\mathrm{Cu}(\mathrm{SCN})_{3}^{-}+2 e^{-} \text {. }
$$

The formation of soluble $\mathrm{Cu}(\mathrm{SCN})_{3}^{-}$apparently occurs through a complex layer consisting of a sandwich type structure, namely an inner $\mathrm{Cu}_{2} \mathrm{O}$ hydrous layer, an intermediate $\mathrm{Cu}(\mathrm{OH})_{2}$ layer and an external CuSCN(s) crystalline phase.

\section{Reactions related to region $I I$}

The extension of region II which lies between $E_{\mathrm{A}_{\mathrm{III}}}$ and $E_{b}$ depends on the concentration of KSCN. The greater the latter the smaller the extension of region II, so that it is practically no longer observed when $c_{\mathrm{KSCN}}$ in larger than $0.5 \mathrm{M}$. In this case pitting occurs simultaneously with current peak $A_{I I I}$. The passive current density $\left(j_{T}\right)$ observed in region II can be assigned to two main processes: the passive film growth $\left(j_{p}\right)$ and the copper electrodissolution as soluble $\mathrm{Cu}(\mathrm{II})\left(j_{c}\right)$ as the latter has been detected using the rrde. At low $v$ values $j_{c} \rightarrow j_{T}$ and $j_{p} \rightarrow 0$ and the fact that $j_{c}$ increases with $c_{\mathrm{KSCN}}$ indicates that $\mathrm{Cu}(\mathrm{II})$ ions are removed from the oxide layer as complex ions through either

$$
\begin{aligned}
\mathrm{Cu}(\mathrm{OH})_{2}+3 \mathrm{SCN}^{-}= & \mathrm{Cu}(\mathrm{SCN})_{3}^{-}+2 \mathrm{OH}^{-} \\
\mathrm{Cu}_{2} \mathrm{O}+\mathrm{H}_{2} \mathrm{O}+6 \mathrm{SCN}^{-}=2 \mathrm{Cu}(\mathrm{SCN})_{3}^{-} & +2 \mathrm{OH}^{-}+2 e^{-}
\end{aligned}
$$



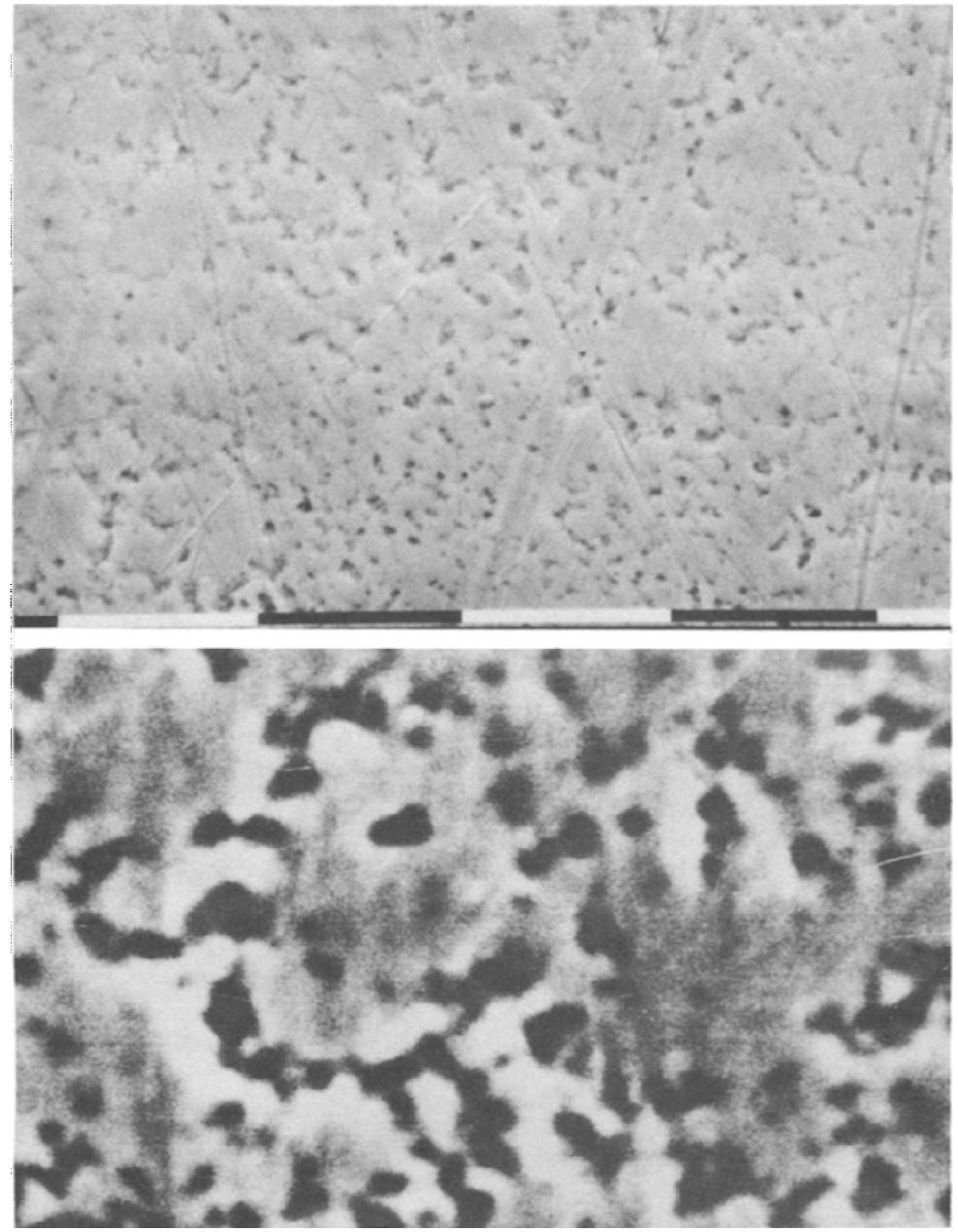

Fig. 14. SEM microphotographs of the copper electrode surface after anodizing at $0.325 \mathrm{~V}$ for $30 \mathrm{~min}$ in the borax buffer $+0.3 \mathrm{M} \mathrm{KSCN}$. The corrosion product was removed by brushing with $0.3 \mu \mathrm{m}$ alumina powder: (upper) scale $10 \mu \mathrm{m}$, (lower) $8000 x$

Both reactions $(5 a)$ and $(5 b)$ comprise the initial weakening of the passive layer leading to passivity breakdown.

\section{Reactions in region $I I I$}

$\mathrm{A} \mathrm{Cu}(\mathrm{SCN})_{2}(\mathrm{~s})$ layer is detected on the electrode at $E_{s}>E_{b}$. The formation of this new phase is related to the initial stage of copper pitting. The potentiostatic current transients recorded in region III exhibit the characteristics of those expected for the nucleation and growth of a new phase on the electrode surface. Therefore pitting can be associated with either the penetration of $\mathrm{Cu}(\mathrm{SCN})_{2}$ nuclei into the passive layer or to passive film removal at defective sites. In these cases reactions (5a) and (5b) can be expressed in more detail as follows

$$
\begin{aligned}
\mathrm{Cu}(\mathrm{II}) \text { passive layer }+2 \mathrm{SCN}^{-} & =\mathrm{Cu}(\mathrm{SCN})_{2}(\mathrm{~s}) \\
\mathrm{Cu}(\mathrm{SCN})_{2}(\mathrm{~s})+\mathrm{SCN}^{-} & =\mathrm{Cu}(\mathrm{SCN})_{3}^{-} \\
\mathrm{Cu}(\mathrm{I}) \text { passive layer }+\mathrm{SCN}^{-} & =\mathrm{CuSCN}(\mathrm{s}) \\
\mathrm{CuSCN}(\mathrm{s})+2 \mathrm{SCN}^{-} & =\mathrm{Cu}(\mathrm{SCN})_{3}^{2}
\end{aligned}
$$

At defective sites the oxide film can be totally removed and the base metal exposed to the electrolyte leading to metal dissolution according to

$$
\mathrm{Cu}^{\circ}+2 \mathrm{SCN}^{-}=\mathrm{Cu}(\mathrm{SCN})_{2}(\mathrm{~s})
$$

followed by reaction (11).

Likewise, $\mathrm{Cu}(\mathrm{SCN})_{3}^{-}(1)$ can be transformed into CuSCN(s) and (SCN) $)_{2}[10]$ according to:

$$
\mathrm{Cu}(\mathrm{SCN})_{3}^{-}(1)=\mathrm{CuSCN}(\mathrm{s})+(\mathrm{SCN})_{2}+e^{-}
$$




$$
3(\mathrm{SCN})_{2}+4 \mathrm{H}_{2} \mathrm{O}=5 \mathrm{SCN}^{-}+\mathrm{SO}_{4}^{2-}+7 \mathrm{H}^{+}+\mathrm{HCN}
$$

Reaction (11) explains the partial inhibition of the pitting process through the deposition of $\mathrm{CuSCN}(\mathrm{s})$ and the $\mathrm{CuSCN}(\mathrm{s})$ and $\mathrm{Cu}(\mathrm{SCN})_{2}$ (s) mixtures detected in the transpassive region[13].

In conclusion, the overall anodization of copper in boric acid - sodium borate buffer containing KSCN, reveals that $\mathrm{SCN}^{-}$ion behaves as an aggressive anion for copper similar to halide ions. The various copper salts and complex soluble ions produced during anodization interfere with the structure of the passivating $\mathrm{Cu}_{2} \mathrm{O} / \mathrm{CuO}$ complex layer causing under certain conditions its rupture and copper electrodissolution at localized sites.

Acknowledgements-INIFTA is a Research Institute jointly established by the Universidad Nacional de La Plata, the Consejo Nacional de Investigaciones Científicas y Técnicas and the Comisión de Investigaciones Científicas de la Provincia de Buenos Aires. M.G.F., visiting professor at INIFTA, thanks the Project "Fortalecimiento del Desarrollo de las Ciencias Químicas", PNUD-UNESCO CHI-84/006 for the grant.

\section{REFERENCES}

1. A. J. Bard (Ed.), Encyclopedia of Electrochemistry of the Elements, Vol. II. Marcel Dekker, New York (1976).

2. R. S. Cooper, J. electrochem. Soc. 103, 307 (1956).

3. R. S. Cooper, J. electrochem. Soc. 105, 109 (1958).

4. A. M. Castro Luna, S. L. Marchiano and A. J. Arvia, $J$. appl. Electrochem. 8, 121 (1978).

5. M. R. Gennero de Chialvo, S. L. Marchiano and A. J. Arvia, J. appl. Electrochem. 14, 165 (1984).

6. B. Miller, $J$. electrochem. Soc. 116, 1675 (1969).

7. H. H. Strehblow and B. Titze, Electrochim. Acta 25, 339 (1980).

8. V. D. Vasquez Moll, M. R. Gennero de Chialvo, R. C. Salvarezza and A. J. Arvia, Electrochim. Acta 30, 1501 (1985).

9. M. R. Gennero de Chialvo, R. C. Salvarezza, V. D. Vasquez Moll and A. J. Arvia, Electrochim. Acta 30, 1011 (1985).

10. J. H. Karchmer (Ed.), Chemical Analysis: Analytical Chemistry of Sulphur and Its Compounds. Parts 1 and 2. Vol. 29, Wiley, New York (1970).

11. M. E. Martins and A. J. Arvia, J. electroanal Chem. 165, 135 (1984).

12. M. R. Gennero de Chialvo, J. O. Zerbino, S. L. Marchiano and A. J. Arvia, J. appl. Electrochem., in press.

13. A. Wey, M. Abramuvith and C. V. D'Alkaine, III Simposio Brasileiro de Electroquimica e Electroanalitica, p. 143 (1983). 